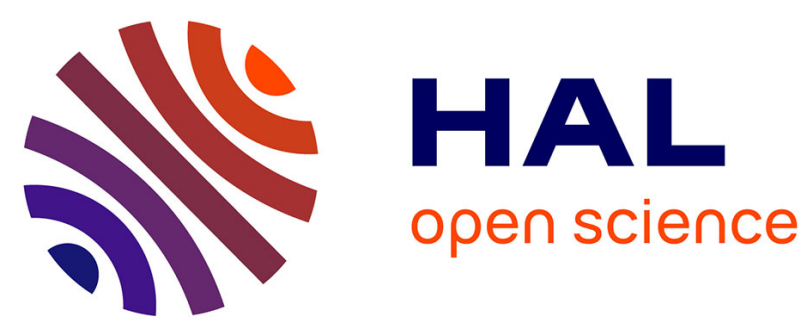

\title{
Study and Development of the Precision Management System for Livestock
}

Fengyun Wang, Wenjie Feng, Jiye Zheng, Huaijun Ruan

\section{To cite this version:}

Fengyun Wang, Wenjie Feng, Jiye Zheng, Huaijun Ruan. Study and Development of the Precision Management System for Livestock. 10th International Conference on Computer and Computing Technologies in Agriculture (CCTA), Oct 2016, Dongying, China. pp.123-133, 10.1007/978-3-03006155-5_12. hal-02180010

\section{HAL Id: hal-02180010 https://hal.inria.fr/hal-02180010}

Submitted on 12 Jul 2019

HAL is a multi-disciplinary open access archive for the deposit and dissemination of scientific research documents, whether they are published or not. The documents may come from teaching and research institutions in France or abroad, or from public or private research centers.
L'archive ouverte pluridisciplinaire HAL, est destinée au dépôt et à la diffusion de documents scientifiques de niveau recherche, publiés ou non, émanant des établissements d'enseignement et de recherche français ou étrangers, des laboratoires publics ou privés. 


\title{
Study and Development of the Precision Management System for Livestock
}

\author{
Fengyun Wang, Wenjie Feng, Jiye Zheng, Huaijun Ruan ${ }^{(\bowtie)}$ \\ S\&T Information Institute, Shandong Academy of Agricultural Sciences, Jinan 250100, \\ Shandong Province, P.R. China \\ wfylily@163.com, 34941269@qq. com, ji yezheng@163.com, rhj64@163.com
}

\begin{abstract}
The article studies the precision management for livestock including breeding, feeding, disease preventing, safety supervision and environmental monitoring. The system based on the wireless mode is developed to monitoring the whole production procedure of livestock. It comprises breeding management, automatic feeding formulation, disease diagnose and prevention, production safety supervision and environmental monitoring subsystems. The study greatly promotes the efficiency of intensive cultivation. Through the practical application in farm, it is proved that the system comprehensive performance is significantly better than the extensive management.
\end{abstract}

Keywords: Precision management, Wireless mode, Livestock, Monitoring

\section{Introduction}

The livestock production is a complex biological system. The livestock produces commercial products and breeds periodically during its whole life. For large scale farm, the production of livestock is like the production in the factory according to the physiological process of breeding. The management should meet the requirements of livestock for the environment, stocking density, feed supply and disease prevention.

With the progress of the intensification and large-scale livestock breeding industry, the traditional management is difficult to process large quantity data, such as environmental parameters, growth data, breeding records, disease information and so on. The outstanding problem is the disease control and product safety in recent years. Especially since entering into WTO, the food safety has become the main obstacles for the export of animal and its products in our country. The main reason is harmful residuals from fodder and contaminant out of limits.

A precision management system is built in this paper. It adopts the modern information, computer and automation technologies to optimize the production process, reduce the input of fodder and veterinary drugs, increase the benefit of enterprise and promote the sustainable development of livestock enterprise. The system integrates the data collection, transmission, analysis, processing and application to realize the visual expression, design, monitor and management of the information. It is successfully applied in farm. 


\section{Overall design}

\subsection{System Requirements Analysis}

The process of livestock production is a periodically, i.e. farrowing, lactation, ablactation, mating, slaughter. During the process, it needs to record and analyze some important information such as the growth data, antiepidemic data, disease data, feeding data, environmental information and so on. The process and requirements are shown in Fig. 1 (which take the pig as an example, below is the same).

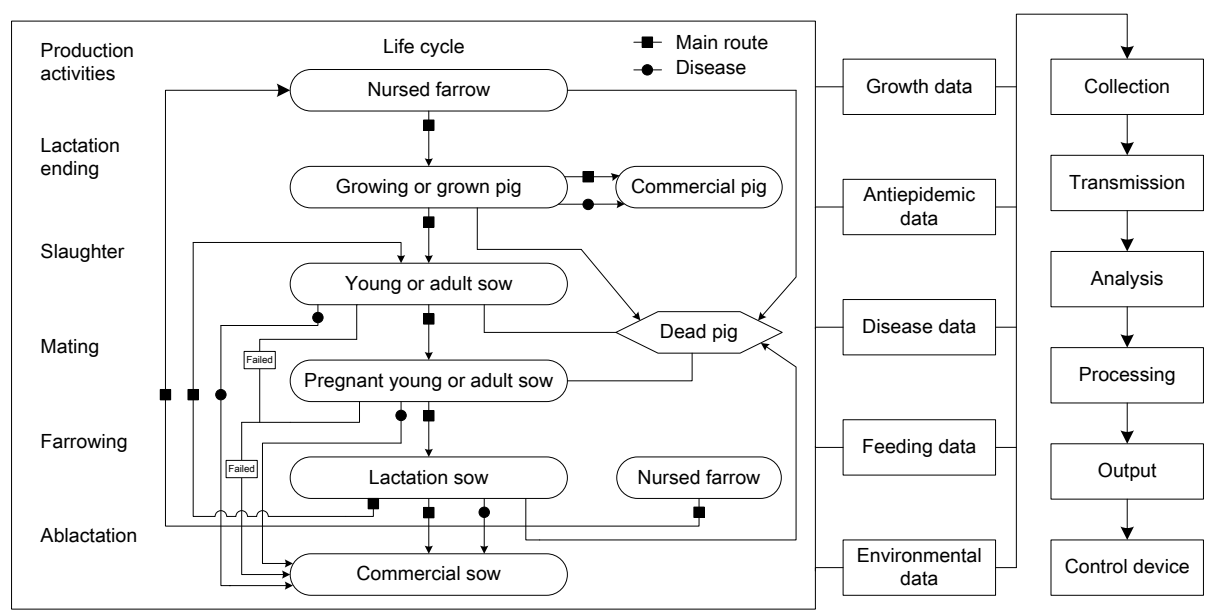

Fig. 1. Process, parameter requirements and control of production system in pig farm

All the data should be stored in the file. Some data is analyzed to generate the decision for feeding, disease presentation and environmental control. The analysis result is used to guide the production. Some results are changed into the order to control the device, e.g. fan, feeder etc.

\subsection{Overall Structure}

In according with the requirements and the above mentioned function demand, this paper integrates the precision management system which includes fodder safety monitoring subsystem, environmental monitoring subsystem, disease diagnose and prevention subsystem, feeding management subsystem and automatic rations formula management subsystem as shown is Fig.2.

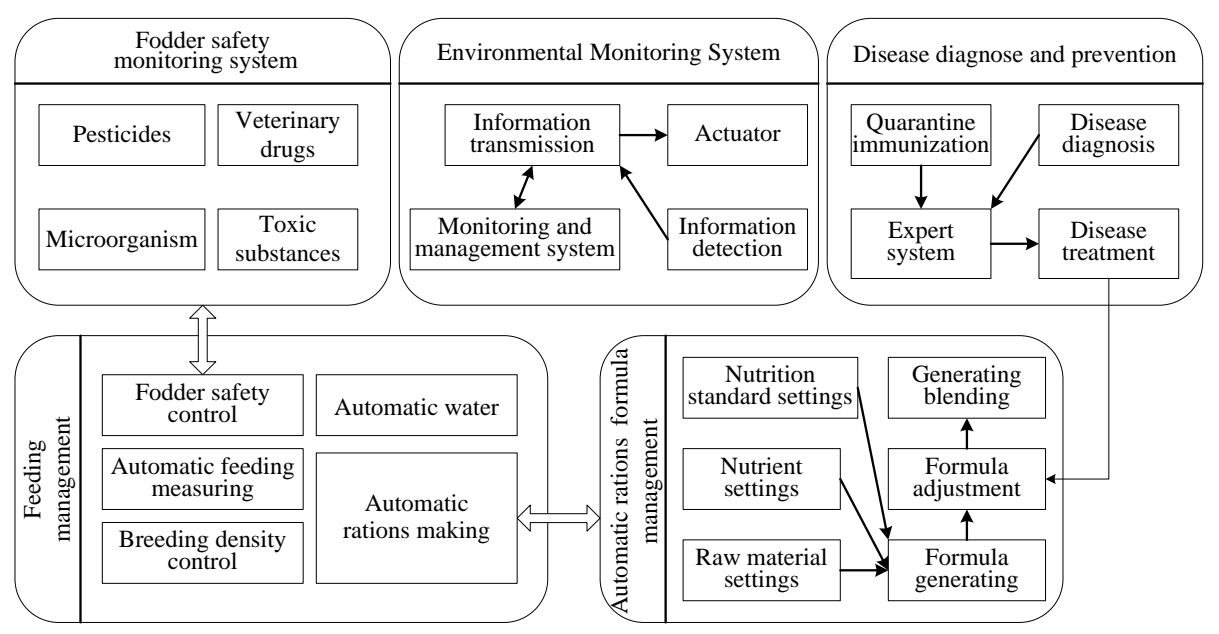

Fig. 2. Overall Structure of Precision Management System 


\section{Precision management system design}

\subsection{Fodder safety monitoring subsystem}

The fodder safety is referred to no toxic or harmful substances or factors existing in the fodder that may be harm to the health or production performance of the animal, such as clenbuterol, microbial toxin, pesticide, heavy metal, mycotoxin and so on.

It is difficult to monitor the safety of fodder because of various kinds of hazardous materials, low content of the toxic or harmful substances and complex fodder ingredients. The implementation of GMP and HACCP promotes the fodder safety monitoring. The important safety information of fodder will be transferred on the internet such as raw material purchase, raw material quality, fodder quality, production process, logistics channel, clients' information feedback, market complaint, quality accident and so on. The fodder safety is ensured by big data analysis from the internet.

\subsection{Automatic rations formula subsystem}

The nutrient requirement is a complex and dynamic process which is affected by the genetic potentiality, food consumption, density of daily ration and growth stage. The formulation of diet is mixed to fodder with balanced nutrition in a certain proportion according to the requirements of various nutrient substance in order to achieve comprehensive nutrition, good taste, low cost and good production effect.

According to Feeding Standard of Swine (NY/T 65-2004), the demand model for pig is built in the system to predict the demand for crude protein, amino acids, minerals, vitamins and fatty acid according to the parameters such as weight, feeding type, type of pig, ambient temperature, aimed daily increased weight and months of age.

The management system firstly calculates the demand quantity of various nutrients according to the demand model, secondly builds the aimed function of diet price according nutritional ingredient database of raw material, thirdly builds the constraint function of diet nutrient demand and proportion and finally gets the original formula through fuzzy linear programming.

Therefore the automatic rations formula management includes the nutrition standard, nutrient ingredient and raw material databases. The nutrition standard database saves the nutrition demand in different growth stage in accordance with (NY/T 65-2004) or adds in different feeding standards. The nutrient ingredient database displays various nutrients through optimal computation according to the prediction model of demand. The raw material database saves various feed proximate composition and price. After the users inputs some basic parameters such as quantity of pig, feed price, type of pig and so on, the system will automatically generate the optimal formula of feed.

\subsection{Disease diagnose and prevention subsystem}

The subsystem tracks the health status of livestock and analyzes the disease synthetically in order that the users can know about the health conditions more quickly and accurately so as to arrange the prevention and treatment for the disease. It realizes the disease report, synthetic analysis, epidemic prevention, disease diagnose and treatment.

The subsystem includes knowledge base, inference engine, database and human machine interface (HMI) as shown in Fig.3.The knowledge base is built by module e.g. disease name, symptom, symptom group, symptom picture, symptom video and rule base etc. Some of the knowledge is descriptive and some is procedural which is 
expressed by computer language and modified gradually in according to the feedback of experts. The inference engine includes the strategy to solve the problem and inference method. It receives the information from the HMI, calls the related knowledge in the knowledge base to process the information according to the records summarized in the database and sends the results to HMI or other output device. HMI changes the information input by the user into the normalized form of expression within the system, then sends them to related module to process and at the same time shows the output information to the user through easily understood external expression form.

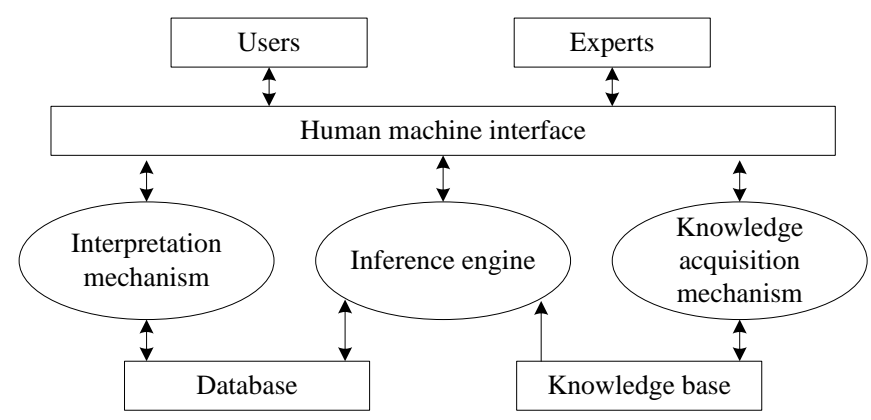

Fig. 3. Flowchart of disease diagnose and prevention subsystem

\subsection{Precise feeding subsystem}

The precise feeding system not only meets the supply of nutrient and maintains the healthy growth but also saves the labor and reduces the waste of fodders. The key technologies of precise feeding subsystem are automatically individual identification, occupied interlock, fodder supply and the strict control of residual fodder. The control flowchart is shown in Fig.4.

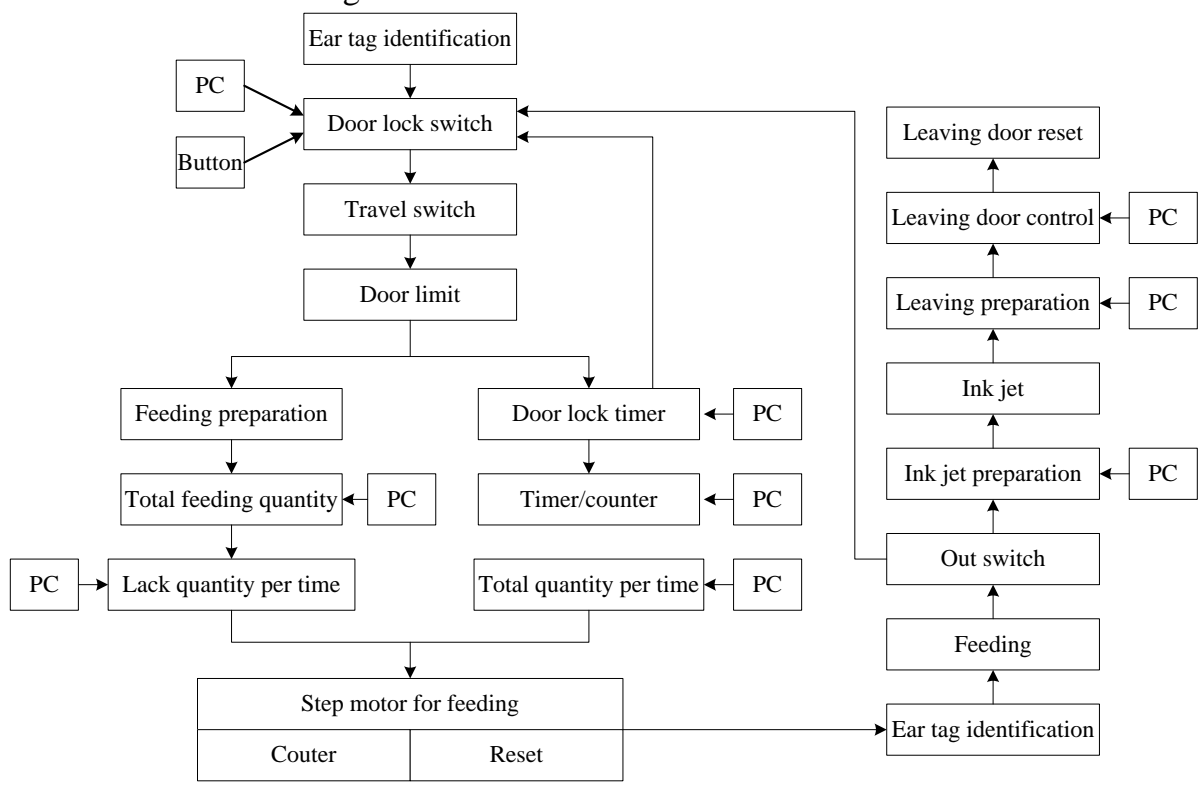

Fig. 4. Control flowchart of precise feeding subsystem

When the animal arrives before the door of feeding device, card reader can detect the signal from the ear tag and send the signal to main controller through serial port. The controller judges whether the animal needs feeding. If it needn't, the door doesn't open. If it needs, the door opens. The animal goes into the feeding device. When there is a signal from travel switch, it shows that the animal enters. After the animal enters, the door is closed automatically to the limit and is locked. The timer of door starts to count and feeding starts. The total daily feeding quantity is calculated by the 
controller in according to artificial intelligence and knowledge base of experts and it also can be set by the PC. The controller judges whether the fodder lacks and how much lacks and sends the signal to the step motor. The motor firstly resets the counter and then starts to count when it drives the belt to feed. The signal of ear tag is detected every $15 \mathrm{~s}$. If the signal isn't detected, stop feeding. Or else continues feeding. After the animal finishes eating, it goes into the leaving area and the card reader will send the leaving signal to the controller which will judge whether the animal ruts or contracts a disease. If there isn't any abnormal condition, the animal will go back to the crowd. Or else the controller will control the ink jet motor to mark on the animal and close the door back to the crowd and open the door of separation. The color of ink is preset by the PC. After the marked animal is separated. The door of separation is closed and the door back to the crowd is opened.

\subsection{Environmental monitoring subsystem}

The growth environment directly affects the health of the livestock, especially in enclosed animal building where the light is limited, the temperature and humidity fluctuate greatly and the harmful gas is difficult to volatilize which greatly affects the growth and propagation of livestock. Therefore it is necessary to accurately monitor the main parameters in real time so as to control the environment such as temperature, humidity, harmful gas and so on.

The subsystem is composed of sensing layer, transport layer and application layer. The sensing layer mainly comprises related sensors and devices to collect the environmental information on site. The information from the sensing layer is sent to the application layer through transport layer to serve for the final application.

The sensing node is the basic unit of wireless sensor network. The sensors mainly are temperature, humidity, H2S, NH3, PM1.0 and PM2.5 sensors. The analog signal from the sensor is converted into digital signal, processed by the microprocessor and interchanged with other network through net application processor (NACP). The application layer is mainly the environmental early warning model and intelligent control model. The core of control model is fuzzy control as shown in Fig.5.

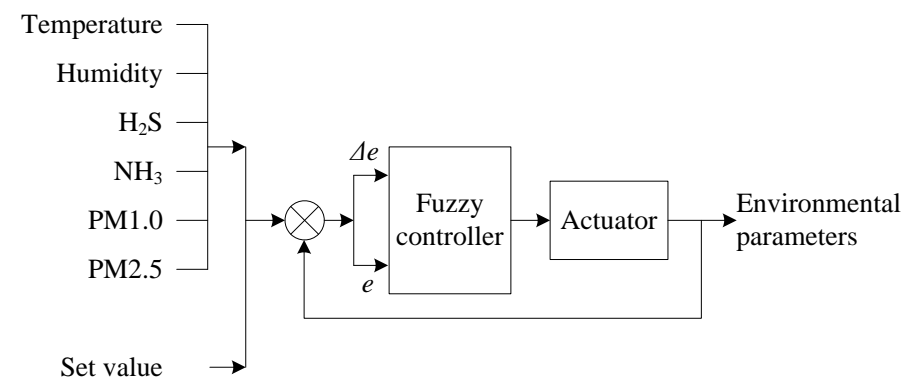

Fig. 5. Fuzzy control schematic diagram

\subsection{Integration of subsystem}

All the subsystem is integrated onto a platform through the internet. The platform includes the data, management, statement analysis and information of swine.

Some data is mainly from the above subsystems, including daily average temperature, daily average humidity, daily average density of $\mathrm{H} 2 \mathrm{~S}$, daily average density of NH3, daily average density of PM1.0, daily average density of PM2.5, daily average weight, daily average increased weight, real monitoring video (Fig.6) and so on. Some data is from input device such as data of death, selection, mating, delivery and ablactation, quantity of farrow, nursery pig and grown pig, sow and nonpregnant sow. The other data is from the alarm of system. 
6

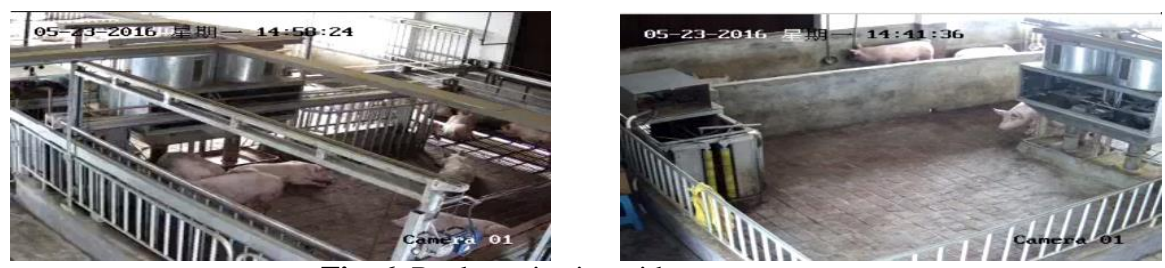

Fig. 6. Real monitoring video

The management includes the files (Fig.7), production and record of some works such as semen collection, hybridization, pregnancy check, delivery, ablactation and so on. The production management includes the record of pig transferring, death (Fig.8), selection, feeding, sale and immunization.

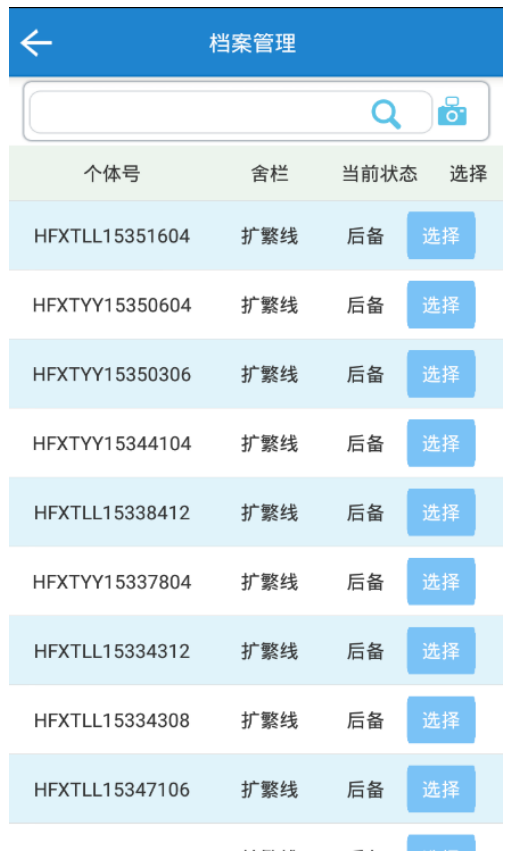

Fig. 7. File management

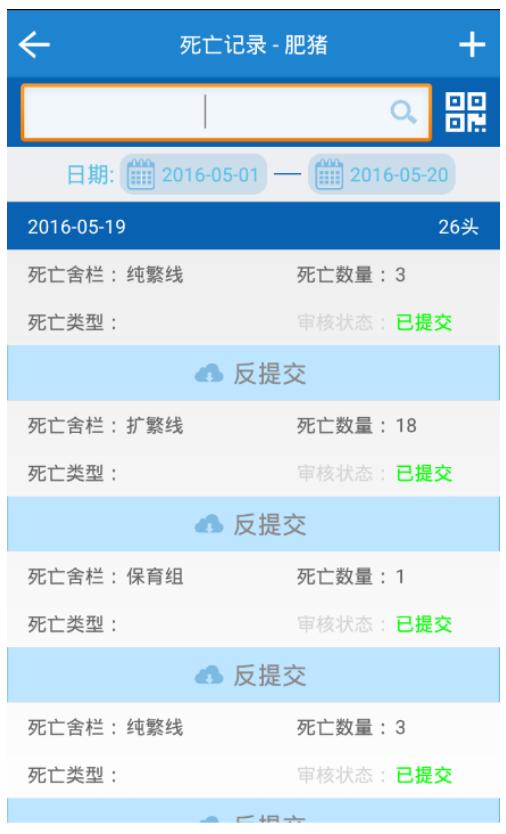

Fig. 8. Record of death

The statement analysis (Fig.9) includes the summarization of amount of livestock, summarization of production, summarization of sale (Fig. 10), daily report of sow production, ladder table, statistic of production, rate of hybridization and delivery, rate of ablactation and hybridization, days of ablactation and nonpregnant, summarization of finishing pig, summarization of sow for hybridization, summarization of sow for delivery, summarization of sow for ablactation, statistic of failed hybridization (Fig. 11), statistic of successful hybridization, statistic of delivery, statistic of death and selection and structure of gestational age (Fig.12). The summarization of amount of livestock includes the present amount of sow (Fig. 13), boar, finishing pigs and total pigs on the farm. The summarization of production includes the condition of hybridization, delivery and ablactation. 

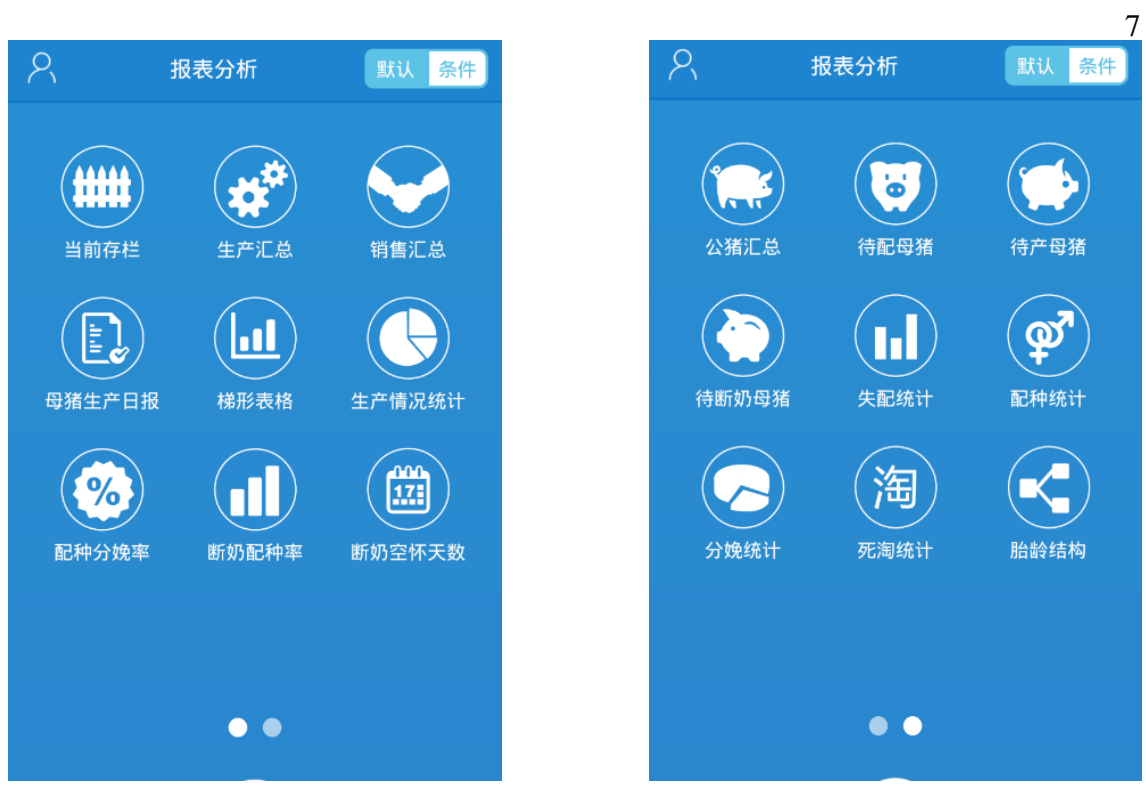

Fig. 9. Statement analysis
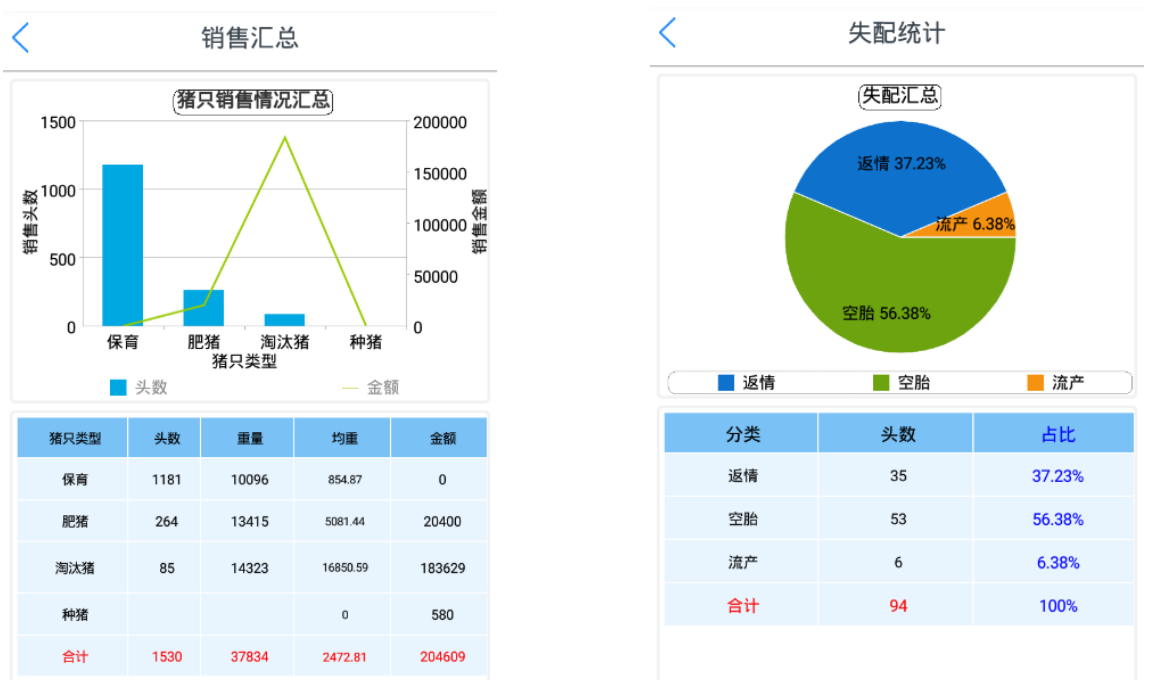

Fig. 10. Summarization of sale

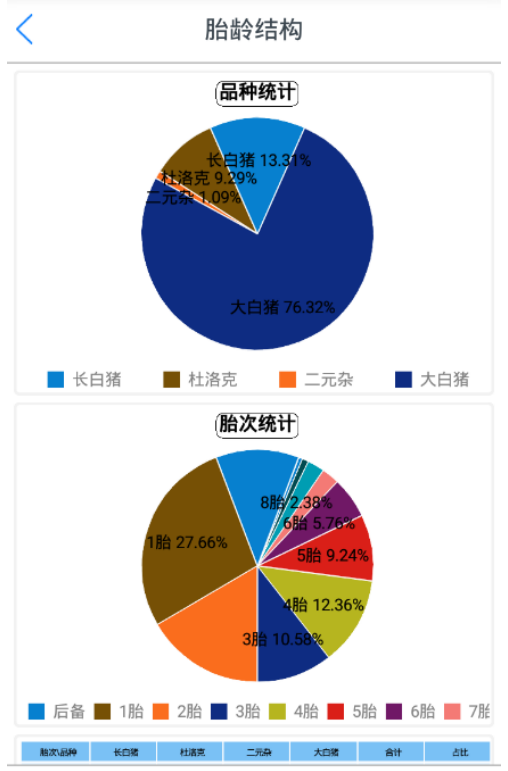

Fig. 11. Statistic of ailed hybridization

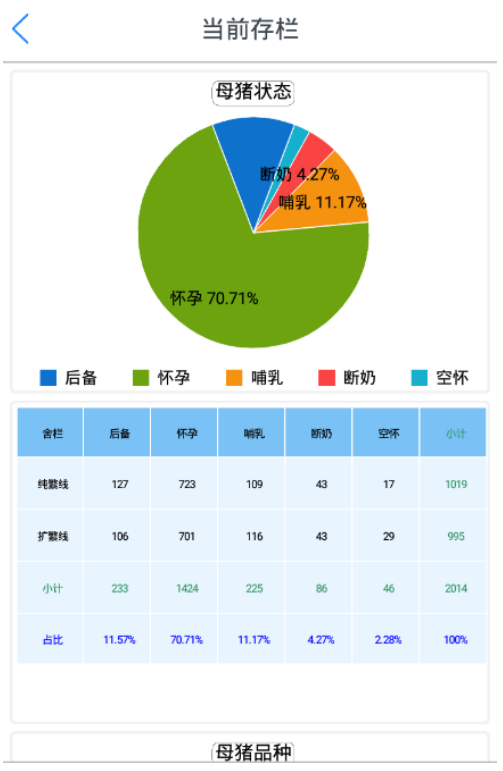

Fig. 12. Structure of gestational age 
The information of swine includes the trend diagram, information of raw material, information of pig price, industry trends, scientific and technological management etc.

\section{Experiments and Discussion}

The precise management system is a comprehensive system which has been applied in the farm successfully. Take the precise feeding subsystem as an example.

The experiment site is in Feicheng City, Shandong Province. The experiments object is the sow separately in three pig houses. There are 25 sows in each pig house where is installed one set of automatically feeding device. The experiment period is 7 days. The daily total feeding quantity is set by the knowledge base in according to the expert. The daily total feeding quantity for different period is shown in Table 1.

Table 1. Daily total feeding quantity for different period

\begin{tabular}{lc}
\hline \multicolumn{1}{c}{ Different period } & Required feeding quantity \\
\hline $10 \mathrm{~kg} \sim 20 \mathrm{~kg}$ & $500 \mathrm{~g}$ \\
$30 \mathrm{~kg} \sim 50 \mathrm{~kg}$ & $800 \mathrm{~g}$ \\
Early stage of pregnancy & $2.0 \mathrm{~kg} \sim 2.2 \mathrm{~kg}$ and nutritional agents \\
Middle stage of pregnancy & $2.4 \mathrm{~kg} \sim 2.5 \mathrm{~kg}$ and nutritional agents \\
Later stage of pregnancy & $2.6 \mathrm{~kg} \sim 2.8 \mathrm{~kg}$ and nutritional agents \\
\hline
\end{tabular}

The controller feeds 2 times every day. If the total quantity of two times doesn't reach the $100 \%$ of set value, the system will provide the third time of feeding. The set value of total daily feeding quantity is $2 \mathrm{Kg}$. Observe the time of feeding and the condition of residual food of each sow crowd every day. For the residual food, it is consider as no residual if the residual is invisible to the naked eye or within $20 \mathrm{~g}$. When the residual is over $20 \mathrm{~g}$, it needs estimate the quantity of residual food.

For the three experimental sow pig houses (separately A, B, C), the observing results of 7 days are shown in Table 2 .

Table 2. Feeding times of sow

\begin{tabular}{ccccccccc}
\hline \multicolumn{8}{c}{ Average daily feeding times in each pig house } \\
& $1^{\text {st }}$ day & $2^{\text {nd }}$ day & $3^{\text {rd }}$ day & $4^{\text {th }}$ day & $5^{\text {th }}$ day & $6^{\text {th }}$ day & $7^{\text {th }}$ day & Average \\
\hline A & 2.211 & 2.200 & 2.143 & 2.077 & 2.078 & 2.126 & 2.082 & 2.131 \\
B & 2.162 & 2.120 & 2.076 & 2.146 & 2.078 & 2.098 & 2.073 & 2.107 \\
C & 2.189 & 2.236 & 2.146 & 2.079 & 2.000 & 2.056 & 2.032 & 2.105 \\
Average & 2.187 & 2.185 & 2.121 & 2.100 & 2.052 & 2.093 & 2.063 & 2.114 \\
\hline
\end{tabular}

It can be seen from the above table that feeding days and different pig house don't affect the feeding of pig. Therefore the feeding time can be set as 2 . The pig can be conditioned after about half month of training. There is about 1 or 2 pigs with residual food through the residual data analysis for 75 pigs in three pig houses which is only $1.8 \%$ of total pig quantity. The feeding days and different pig house don't affect the residual food of pig. There may be some external factors affecting the feeding and residual such as snarl of pig, disease, oestrus, suddenly outage of power supply and so on. But it doesn't affect the normal operation of control system.

\section{Conclusions}

The precise management system is a comprehensive, easily operating, easily updating and easily managing system. It uses the electric ear tag to identify each pig and provides the functions of fodder safety monitoring, automatic rations formula, disease diagnose and prevention, precise feeding, environmental monitoring and system management which realize the whole process control for swine production, reduce the manpower and lower the feeding cost. The precise management system provides the 
technology support for cultivation with high yield, high quality and high efficiency which will greatly promote the livestock industry developing towards intelligence.

\section{Acknowledgment}

Funds for this research was provided by the Key Research and Development Plan of Shandong Province (2016GNC110008, 2016CYJS03A01-1), Agricultural Science and Technology Innovation Project of Shandong Academy of Agricultural Sciences (CXGC2017B04), Shandong Academy of Agricultural Sciences (SAAS) Youth Scientific Research Funds Project (2015YQN58), Key Applied Technological Innovation Project in Agriculture of Shandong: Key Technology Research and Development of Intelligent Control for Healthy Broiler Production in Greenhouse.

\section{References}

1. Zheng Hongjian, Xue Fei, Yang Lixin. Research on the information management system of culture and production process of breeding pigs and its application [J]. Journal of Anhui Agriculture Science, 2009, 37(14):6658-6659 (in Chinese).

2. Olsson A C, Andersson M, Botermans J, et al. Animal interaction and response to electronic sow feeding (ESF) in 3 different herds and effects of function settings to increase capacity [J]. Livestock Science, 2011, 137(1-3):268-272.

3. Yang Liang, Xiong Benhai, Cao Pei, et al. Design and experiment of electromechanical control system of automatic feeder for gestation sow [J]. Transactions of the Chinese Society of Agricultural Engineering, 2013, 29(21):66-71 (in Chinese).

4. Liu Beijiang. Air safety control technology and application for environmental safety type pig house. Swine Industry Outlook, 2014, 909:70-74(in Chinese)

5. Li Yongzhi. Safety control technology of feed hygiene [J]. The Chinese Livestock and Poultry Breeding, 2011, 707:88-90 (in Chinese).

6. Liu Jiawei. A research on feed safety supervision system [D]. Huazhong University of Science and Technology, 2011 (in Chinese).

7. Chen Ming. Study on nutrient diagnosis and diet formula optimizing system of swine [D]. Chinese Academy of Agricultural Sciences, 2011 (in Chinese).

8. Ma Jinghan, Chen Cunren, Wang Ying, et al. Research on liguid feeding system for largescaled intensive pig farm [J]. Transactions of the Chinese Society of Agricultural Engineering, 2006, S2:88-91 (in Chinese).

9. Soldatos A G, Arvanitis K G, Daskalov PI, et al. Nonlinear robust temperature -humidity control in livestock buildings [J]. Computers and Electronics in Agriculture, 2005, 49(3):357 -376

10.Zhang Wei, He Yong, Liu Fei, et al. The environmental control system based on IoT for scale livestock and poultry breeding [J]. Journal of Agricultural Mechanization Research, 2015(2):245-248 (in Chinese).

11.Zhang Qian, Yang Xianglong, Zhou Yiming, et al. A wireless solution for greenhouse monitoring and control system based on ZigBee technology [J]. Journal of Zhejiang University Science A， 2007， 8(10):1584-1587.

12. Juan Ignacio Huircán, Carlos Mu Oza, Héctor Younga, et al. ZigBee-based wireless sensor network localization for cattle monitoring in grazing fields [J]. Computers and Electronics in Agriculture, 2010, 74(2): 258-264.

13. Li Lifeng, We Pei, Ma Shuoshi, et al. Monitoring and controlling system for delivery sow house environment based on configuration software and fuzzy control [J]. Transactions of the Chinese Society of Agricultural Engineering, 2011, 27(6):231-236 (in Chinese).

14.Zhang Ruiqing, Zhang Yanxia, Wang Wendi, et al. Research on automatic monitoring system of ammonia concentration in pig house [J]. Journal of Agricultural Mechanization Research. 2008, (4): 134-136 (in Chinese).

15. Daskalov P I, Arvanitis K G, Pasgianos G D, et al. Non-linear adaptive temperature and humidity control in animal buildings [J]. Biosystems Engineering, 2006, 93(1): 1-24.

16. Qian Dongping, Wang Jianxin, Sui Meili, et al. Implement of temperature fuzzy control system for animal building [J]. Transactions of the Chinese society of agricultural machinery, 2005, 36(12):95-98.

17. M Woloszyn, T.Kalamees, M.OlivierAbadie, et al. The effect of combining a relative- 
humidity-sensitive ventilation system with the moisture-buffering capacity of materials on indoor climate and energy efficiency of buildings [J]. Building and Environment, 2009, 44(3): 515-524.

18. X.Shen, G.Zhang, W.Wu, et al. Model-based control of natural ventilation in dairy buildings [J]. Computers and Electronics in Agriculture, 2013, (94):47-57.

19. I.Seoa, I.-b.Lee, O.-k.Moon, S.-W.Hong. Modelling of internal environmental conditions in a full-scale commercial pig house containing animals [J]. Biosystems Engineering. 2012 (111): 91-106. 